\title{
Post-stroke Quality of Life Index: A quality of life tool for stroke survivors from Sri Lanka
}

\author{
P.K.B. Mahesh ${ }^{1 *}$ D, M.W. Gunathunga ${ }^{2}$, S. Jayasinghe ${ }^{3}$, S.M. Arnold ${ }^{1}$ and S.N. Liyanage ${ }^{4}$
}

\begin{abstract}
Background: Burden of stroke is rising due to the demographic and epidemiological transitions in Sri Lanka. Assessment of success of stroke-management requires tools to assess the quality of life (QOL) of stroke survivors. Most of currently used QOL tools are developed in high-income countries and may not reflect characteristics relevant to resource-constrained countries. The aim was to develop and validate a new QOL tool for stroke survivors in Sri Lanka.
\end{abstract}

Methods: The COnsensus-based Standards for the selection of health Measurement Instruments (COSMIN) checklist was referred. A conceptual framework was prepared. Item generation was done reviewing the existing QOL tools, inputs from experts and from stroke survivors. Non-statistical item reduction was done for the 36 generated items with modified-Delphi technique. Retained 21 items were included in the draft tool. A cross sectional study was done with 180 stroke survivors. Exploratory Factor Analysis was done and identified factors were subjected to varimax rotation. Further construct validity was tested with 6 a-priori hypothesis using already validated tools (SF-36, EQ-5D-3 L) and a formed construct. Internal consistency reliability was assessed with Cronbach alpha.

Results: Four factors identified with principal-component-analysis explained 72.02\% of the total variance. All 21 items loaded with a level > 0.4. The developed tool was named as the Post-stroke QOL Index (PQOLI). Four domains were named as "physical and social function", "environment", "financial-independence" and "pain and emotional-wellbeing". Four domain scores of PQOLI correlated as expected with the SF-36, EQ-5D Index and EQ-5DVAS scores. Higher domain scores were obtained for ambulatory-group than the hospitalized-group. Higher scores for financial-independence domain were obtained for the group without financial-instability. Five a-priori hypothesis were completely proven to be true. Cronbach-alpha level ranged from 0.682 to 0.906 for the four domains.

Conclusions: There is first evidence for sufficient construct validity of the PQOLI as a valid QOL tool for measuring the QOL of stroke survivors with satisfactory internal consistency reliability.

Keywords: PQOLI, Stroke, Tool development and validation, Quality of life, Sri Lanka

\section{Introduction}

Stroke is a rapid vascular event with symptoms lasting $24 \mathrm{~h}$ or longer [1]. Stroke is regarded as a major cause of disability anywhere in the world [2]. Its burden has been

* Correspondence: buddhikamaheshpk@gmail.com

${ }^{1}$ Office of Regional Director of Health Services, Colombo, Sri Lanka

Full list of author information is available at the end of the article relatively worsening in low- and middle-incomecountries (LMICs) compared to high-income countries (HICs) in relation to its incidence as well as social and economic impacts [3]. As an example when a decrease of $42 \%$ of stroke incidence is observed in HICs, an increase over $100 \%$ is observed in LMICs over the last four decades [3]. Sri Lanka was recently upgraded as a

C C The Author(s). 2020 Open Access This article is licensed under a Creative Commons Attribution 4.0 International License, which permits use, sharing, adaptation, distribution and reproduction in any medium or format, as long as you give appropriate credit to the original author(s) and the source, provide a link to the Creative Commons licence, and indicate if changes were made. The images or other third party material in this article are included in the article's Creative Commons licence, unless indicated otherwise in a credit line to the material. If material is not included in the article's Creative Commons licence and your intended use is not permitted by statutory regulation or exceeds the permitted use, you will need to obtain permission directly from the copyright holder. To view a copy of this licence, visit http://creativecommons.org/licenses/by/4.0/ The Creative Commons Public Domain Dedication waiver (http://creativecommons.org/publicdomain/zero/1.0/) applies to the data made available in this article, unless otherwise stated in a credit line to the data. 
Upper-Middle Income Country after being a LMIC with comparatively satisfactory health parameters $[4,5]$. Prevalence of stroke in urban Sri Lanka was estimated to be 10.4 per $1000(95 \% \mathrm{CI}=6.3$ to 14.5$)$ with a male to female ratio of 2:1 [6]. Relatively higher incidence of stroke among the young also been noted here [7]. With the demographic and the epidemiological transitions, as in many other LMICs, stroke burden is expected to rise further in future.

The World Health Organization (WHO) defines Quality of Life (QOL) as "the individual's perception of his/ her position in life in the context of the culture and value systems in which they live and in relation to their goals" [8]. It is a composite concept affected by many facets [8]. In a patient with a disease condition, the QOL may reflect the success of management of that particular disease, as the patient perceives [9]. Disabilities imposed by stroke would directly or indirectly influence the physical as well as psychological QOL components as perceived by the patients. Hence the QOL of stroke survivors is an extremely important factor, for research, to assess progress and to target services for stroke survivors [10-12].

Since QOL is a patient-reported outcome, there is no agreement on exactly which domains are to be captured within its scope [13]. Hence, though there are many available QOL tools, there is much variability among their domains [14, 15]. Environmental influences (such as user-friendliness and safety of household items) and economic influences (such as financial security), do affect the "self-perceived position in life", especially in disability-related conditions like stroke. Many QOL tools do not capture these, even though these are proved to impose an impact on overall QOL [16-22]. It has been encouraged to design QOL instruments specially including domains like economic costs and burden to the family members [23]. Furthermore, epidemiological characteristics of stroke are prone to vary even within LMICs [24, 25]. The living contexts (i.e. standards of household environment and items) and the expectations of the people (i.e. due to the differences in salary scales and in social insurance systems) are different between the HICs and LMICs. Stroke-related literature is scarce in relation to LMICs. Hence most of the evidence on stroke rehabilitation which come from Western settings which might not be applicable for lower-middle income settings [26-30]. The development of new QOL tools for stroke survivors would enable more context-related QOL measurements [31].

Out of the many health-related QOL tools available, Short-Form-36 (SF-36) and European Quality of Life 5 dimensional (EQ-5D) tool are two commonly used generic tools [9, 32-34]. SF-36 includes 08 scales and has been used to assess QOL in stroke survivors following hospital discharge [35-39]. It has been validated for several disease conditions including stroke within Sri Lanka [37, 40]. EQ-5D tool consists of an EQ-5D descriptive system as well as an EQ-Visual-Analogue-Scale (VAS). The former system include five dimensions and the latter records the respondent's self-rated health on a VAS [41]. It too has been validated within Sri Lanka [42, 43]. SF-36 covers a period of 28 days previous to the date of data collection and the EQ-5D captures the QOL related to the time of data collection.

Validity, reliability and responsiveness are three properties that must be evaluated in relation to a newly developed measurement tool [44, 45]. Validity measures whether the tool "actually measures what it is expected to measure" [46]. In the absence of a gold standard test for QOL, the validity based on data is assessed by the construct validity [47]. Reliability refers to a measure of inherent amount of error of any measurement [48]. It includes the assessment of homogeneity of each of the items measured by Cronbach Alpha and reproducibility (measured with test-retest method etc.) [48, 49]. Responsiveness is defined as the ability to detect a clinically important change $[50,51]$.

Sri Lanka is trying to expand stroke-related services in general including that of acute care, rehabilitation and community-based care [52]. Availability of contextspecific QOL tools would greatly help in assessing the success of management of stroke survivors in this context. The aim of the study was to develop and validate a comprehensive quality of life tool for stroke survivors at post-stroke 1-month in Sri Lanka.

\section{Methods}

\section{Conceptual framework and item generation}

The COnsensus-based Standards for the selection of health Measurement Instruments (COSMIN) checklist was referred [44, 45]. The literature was searched using electronic databases (PUBMED and MENDELEY) with relevant key words (Supplementary file-I). General and specific tools that measure QOL of the stroke survivors were noted. Having studied the variables/domain of the identified tools, inputs from key informants and clients (three survivors of stroke and two caregivers), a conceptual framework was developed (Fig. 1). The identified domains were within the scope of the interpretation of QOL by the WHO [8].

Using the conceptual framework, items were generated and listed by reviewing the items of identified tools, getting additional inputs from expert key-informants and clients mentioned above. Items were expected to cover the quality of life of a period of 7 days of the stroke survivors' life, from the time of interview.

In all the above processes inputs were taken from a panel of seven key informants who were experts related 


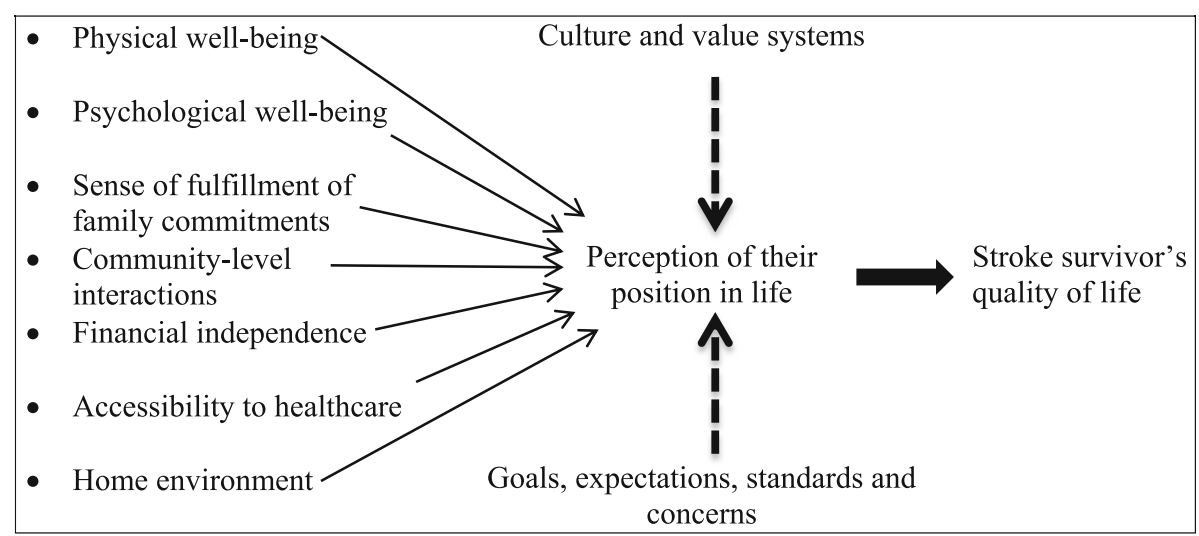

Fig. 1 Conceptual framework

to the stroke care. The panel included two consultants in neurology in the premier tertiary hospital of Sri Lanka, one consultant in clinical medicine and anesthesiology from the same setting. Furthermore it included a professor in community medicine and a lecturer in sociology in a premier university as well as a general practitioner.

\section{Non-statistical item reduction and drafting the questionnaire}

Similar items were combined. This draft list was sent to the eight experts (i.e. seven above mentioned panel members and another nominated by them) above with modified Delphi technique through emails. They were asked to rate each item with a five-point scale based on the relevance of the question to the local setting (i.e. from least relevant to extremely relevant) and to send back their ratings through email. The items whose average scores were within the first quartile were omitted.

The stems were drafted for these items in par with both an interviewer-administered and a self-administered questionnaire. It is highlighted in the literature, that a tool, being able to be used as both self and interviewer administered, is important in relation to stroke [53]. The concepts described by Streiner and Norman (2008), like conceptual equivalence, item equivalence, semantic equivalence and translation procedures were considered in drafting the stems [54]. The questions were originally formed in English and then translated to Sinhalese. The forwardand- backward-translation method was used adhering to the recommended measures [55].

Five response categories were used for each stem. The response categories ranged from "Always" to "Not at all". A scoring system from 1 to 5 with 1 representing the worst QOL and 5 representing the best was developed. Stems representing negative phenomena were reverse coded. The items thus generated, were given to the panel of experts to allocate a mark out of 10 per each item in relation to the wording and clarity.

\section{Data collection and factor analysis}

A cross sectional study was carried out in two settings to explore the factor structure of the draft instrument. The rehabilitation unit of the Colombo North Teaching Hospital was one setting. Residential rehabilitation services for the stroke survivors are available here. The other setting was the neurology clinics of the National Hospital of Sri Lanka where the ambulatory care is given for patients after the discharge from the hospital. Stroke survivors who were within 28 days to 32 days following the acute phase of their management were selected to the study leaving a margin of 2 days from either side of the intended period of 1 month. In order to obtain reliable estimates, it has been mentioned that a minimum subject to item ratio of $1: 5$ is needed for exploratory factor analysis [56]. Since the interviewer-administered questionnaire contained 21 retained questions it was decided to have 7.5 times of the number of variables making the sample size as 157 considering the feasibility of data collection. With an assumed response rate of $90 \%$, the sample size at the data collection stage was decided to be 180 . The participants who were managed at study settings from 1st of December 2014 were eligible to be included in the study.

\section{Exploratory factor analysis}

Data was entered in to a Statistical Package of Social Sciences (version 17) datasheet. Factorability was assessed using the Kaiser-Meyer-Olkin (KMO) measure of sample adequacy, Bartlett's test of sphericity and anti-image correlations [57]. Exploratory Factor Analysis with Principal Component Analysis was done. We retained factors whose Eigenvalues were greater than 1 . Having studied the scree plots, the selected factors were subjected to 
varimax rotation. The subsequent factor loadings were examined.

The draft instrument was pre-tested among 10 stroke survivors. Following the administration of the questionnaire, the investigators had a brief interview with them on the wording of items of the questionnaire. Based on the responses, the final adjustments were done in relation to the clarity of wording.

\section{Further assessment of validity and reliability of the developed tool}

The three aspects of the judgmental validity; face, content, consensual (i.e. agreement between experts) were assessed with the inputs of the panel of experts [47]. The data-based further construct-validity was assessed using the findings of SF-36, EQ-5D and the questions on financial burden.

Six a-priori hypotheses were used.

1. The domain scores of the developed tool will have statistically significant positive correlations with all domains of SF-36

2. The domain scores of the developed tool will have statistically significant positive correlations with EQ-5D index score

3. The domain scores of the developed tool will have statistically significant positive correlations with EQ-5D VAS score

4. The domain scores of the developed tool will correlate with more-related domains with a higher strength of association than the scores of other domains.

The a-priori hypotheses from no. 1 to no. 4 were evaluated by testing the construct validity with the findings of SF-36 and EQ-5D-3-Level tools.
5. The domain scores of the developed tool will be statistically significantly higher for the ambulatory group than the hospitalized group. The hypothesis no.05 tested the ability of the tool to discriminate between the two ends of the severity spectrum, as another aspect of construct validity. For this, the domain scores of the institutionalized participants and the ambulatory participants were compared.

6. There will be a statistically significant difference of the financial domain scores between the groups with financial burden at family level and those who are not. The sixth was evaluated by a set of four judgmentally-validated questions composed by reviewing the literature on financial burden [58]. The questions were; whether the participant had to apply for a loan, whether the participant had to sell a property, whether the participant had a reduction of income and whether the participant had to restrict the expenses for other usual matters due to the impact of the disease condition. The presence of any of these was noted as presence of financial burden at family-level.

This procedure of adopting a-priori hypotheses was similar to the methodology adapted in many other global validation studies [59-62]. Satisfactory confirmation of two thirds of the hypotheses at least was considered as necessary for sufficient construct validity.

Internal consistency reliability was assessed by calculating the Cronbach alpha coefficient. Internal consistency estimates of a magnitude of 0.70 or greater was considered as satisfactory [63]. Level of significance was considered as 5\%. Ethical clearance was obtained

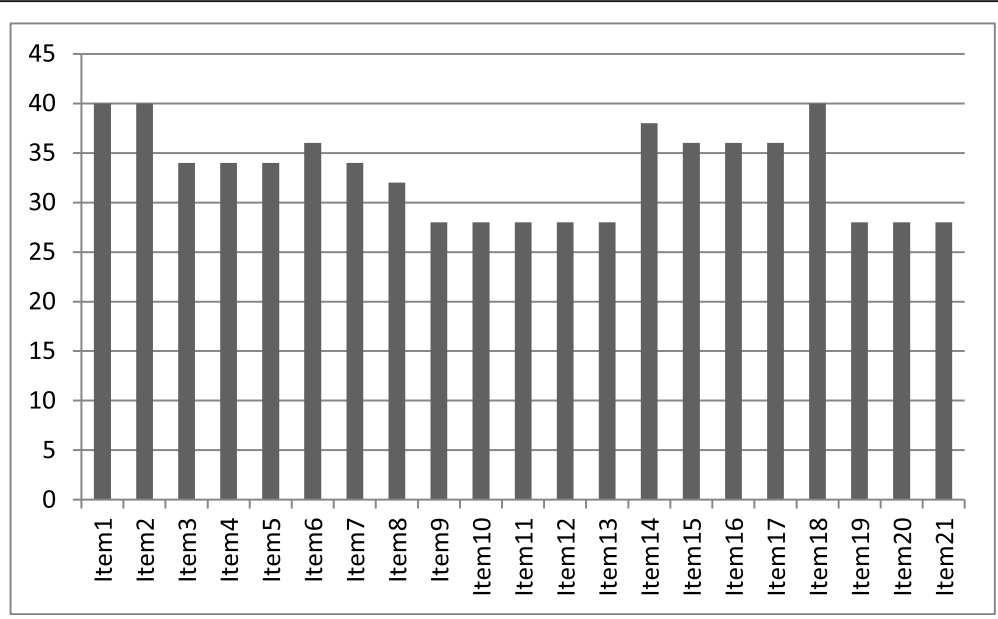

Fig. 2 Cumulative scores given by the expert panel for the selected items ( $x$ axis corresponds each item and the $y$ axis shows the cumulative score) 
Table 1 Factor structure analysis of the tool (each item corresponds to the respective question number of the PQOLIas shown in Table 3)

\begin{tabular}{|c|c|c|c|c|}
\hline & Factor 1 & Factor 2 & Factor 3 & Factor 4 \\
\hline Item1 & .858 & .237 & .191 & .163 \\
\hline Item2 & .886 & .228 & .175 & .103 \\
\hline Item3 & .852 & .187 & .221 & .134 \\
\hline Item4 & .540 & .077 & .167 & .341 \\
\hline Item5 & .838 & .102 & .185 & .147 \\
\hline Item6 & .859 & .008 & .043 & .101 \\
\hline Item7 & .750 & .234 & .302 & .048 \\
\hline Item8 & .613 & .448 & .453 & .065 \\
\hline Item9 & .590 & .526 & .291 & .061 \\
\hline Item10 & .491 & .508 & .428 & -.176 \\
\hline Item11 & .482 & .245 & .642 & .087 \\
\hline Item12 & .219 & .151 & .781 & -.014 \\
\hline Item13 & .167 & .084 & .854 & .049 \\
\hline Item14 & .512 & .231 & -.002 & .508 \\
\hline Item15 & .095 & .222 & 691 & .303 \\
\hline Item16 & .471 & .254 & .308 & .476 \\
\hline Item17 & .138 & -.006 & .088 & .863 \\
\hline Item18 & .167 & .752 & .273 & .069 \\
\hline Item19 & .096 & .863 & -.016 & -.019 \\
\hline Item20 & .142 & .859 & .172 & .127 \\
\hline Item21 & .211 & .784 & .179 & .135 \\
\hline
\end{tabular}

from the Ethics Review Committee of the Medical Research Institute of Sri Lanka (Reference 60/2014). The procedures followed were in accordance with institutional guidelines of the study settings. Informed written consent was obtained from the participants.

\section{Results}

The domains of QOL that have been included in the tools found in literature search have been listed in Supplementary file 2 [10, 53, 64-68].

After combining the related items, the initial list included 36 items. The mean and median cumulative scores given by the expert panel through the modifiedDelphi technique for the initial item list was 22 and 28 respectively. The upper margin of the first quartile was 7. The number of items which scored more than the upper first quartile was 21. Figure 2 shows the distribution of the cumulative scores given by the experts. No outliers were detected for the scores on clarity and wording.

It took in average $20 \mathrm{~min}$ for an interview with a participant. The median (Inter Quartile Range) age of the sample was 56 (46-65). The total respondents were 180 with the male to female ratio of the participants being approximately 2.8 to 1 (73 to $27 \%$ ). The proportions of missing values ranged from 1.1 to $11.1 \%$. The KMO measure of sampling was 0.876 and the Barlett test of sphericity was significant $(p<0.001)$. The diagonal anti-image correlation ranged from 0.611 to 0.943 . Following the factor analysis, four factors were detected with an eigenvalue more than 1. Out of those 04, the maximum eigenvalue was 10.051 and the least value was 1.182 . Out of the total variance, $72.02 \%$ was explained by the cumulative variance of these four factors. All the 21 items loaded with a level $>0.4$ into the selected four components. Hence no further statistical item reduction was done.

The factor structure analysis of the 21 items is mentioned in Table 1.

Considering the factor loadings and the correlations of the factors, items were assigned into the respective factors. The complex variables were retained in the best factor as suggested by the Cronbach alpha values with

Table 2 Correspondence of the retained items to the four domains

\begin{tabular}{|c|c|c|c|c|}
\hline & Domain I & Domain II & Domain III & Domain IV \\
\hline Given name & Physical and social functioning & Environment & Financial independence & Pain and emotional well-being \\
\hline Included no. of items & 10 & 4 & 4 & 3 \\
\hline \multirow[t]{10}{*}{ Item numbers } & Item 1 & Item 18 & Item 11 & Item 14 \\
\hline & Item 2 & Item 19 & Item 12 & Item 16 \\
\hline & Item 3 & Item 20 & Item 13 & Item 17 \\
\hline & Item 4 & Item 21 & Item 15 & \\
\hline & Item 5 & & & \\
\hline & Item 6 & & & \\
\hline & Item 7 & & & \\
\hline & Item 8 & & & \\
\hline & Item 9 & & & \\
\hline & Item 10 & & & \\
\hline
\end{tabular}


Table 3 The PQOLI tool

Questions are covering the last 7 days
1. My illness/s have a negative effect
ony ability to walk and move around
2. My illness/s have a negative effect on
the ability i used to have to look after my
3. My illness/s have a negative effect on
my ability to select foods, cook, serve or to
eat that I used to have

4. My illness/s have a negative effect in having a sound sleep

5. My illness/s have a negative effect in my ability to have sexual activities that I used to have

6. My illness/s cause discomfort in proper toilet practices

7. My illness/s have a negative effect on my ability to communicate with others

8. My illness has restricted me performing previous roles I played in my family

9. The society assumes that I am not capable of performing social activities that I used to do due to my illness

Best responses
Not at all
Rarely
Occasionally
Frequently
Always

Table 3 The PQOLI tool (Continued)

Questions are covering the last 7 days
previous recreational activities I used to have
11. My income-generation activities are
restricted by the illness
12. I am worried about the restrictions on
life by having to be on regular attention
(medications, attending clinics, getting
investigations)

Always

Not at all

Rarely

Occasionally

Frequently

Always

Not at all

Rarely

Occasionally

Frequently

Always

Not at all

Rarely

Occasionally

Frequently

Always

Not at all

Rarely

Occasionally

Frequently

Always

Not at all

Rarely

Occasionally

Frequently

Always

Not at all

Rarely

Occasionally

Frequently

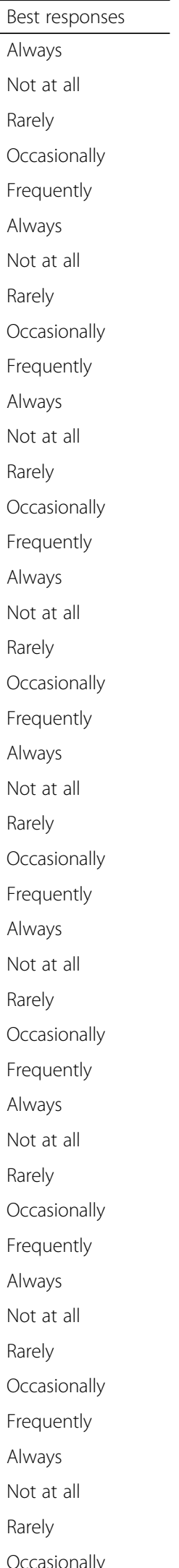


Table 3 The PQOLI tool (Continued)

\begin{tabular}{ll}
\hline Questions are covering the last 7 days & Best responses \\
\hline & Frequently \\
& Always \\
19. The living environment of my house & Not at all \\
(floor, stairs, space) is not user-friendly & Rarely \\
considering my health condition & Occasionally \\
& Frequently \\
& Always \\
20. I am worried about the transport in & Not at all \\
accessing health care & Rarely \\
& Occasionally \\
& Frequently \\
21. I have no restriction or problem in & Always \\
getting the medical care (medical advice, & Not at all \\
drugs, investigations) & Rarely \\
& Occasionally \\
& Frequently \\
& Always
\end{tabular}

"items removed". The Table 2 summarizes the correspondence of the retained items to the individual domains.

The developed tool was named as "Post-stroke Quality Of Life Index for strokes survivors" (PQOLI) (Table 3).

The measures of location and measures of dispersion were obtained as shown in Table 4. All domain scores have a potential range from 0 to 100 .

Table 5 shows the spearman-correlation of the domain scores with the scores of SF-36 and the EQ-5D tools.

All domains showed statistically significant positive correlations with scores of SF-36 and EQ-5D-3 L. The EQ-5D-3 L scores had relatively higher strength of associations for the Domains I and IV. In general, for the domain scores with more similar constructs of the SF-36, the associations were with relatively higher strengths.

The ability to discriminate between the two ends of the severity spectrum of a disease entity is mentioned in Table 6. It shows that the QOL was significantly higher in the ambulatory group than the institutionalized group.

In the study sample, $27 \%(n=49)$ had to apply for a loan, $30 \%(n=54)$ had to sell a property, $67 \%(n=120)$ had a potential income loss and $67 \%(\mathrm{n}=120)$ had to

Table 4 Characteristics of the domain scores of the PQOLI tool

\begin{tabular}{lllll}
\hline Domain & Mean & Standard deviation & Median & Inter-Quartile Range \\
\hline I score & 56.17 & 22.35 & 53.00 & $40.00-72.00$ \\
II score & 58.15 & 20.23 & 60.00 & $40.00-70.00$ \\
III score & 44.25 & 16.74 & 40.00 & $33.75-55.00$ \\
IV score & 66.93 & 20.69 & 66.67 & $53.33-86.67$ \\
\hline
\end{tabular}

restrict other expenses, due to the illness. Approximately $73 \%(n=133)$ had a financial burden. Higher values for the financial-domain-score were obtained by those who did not experience a financial burden. The median (IQR) financial-domain-scores of PQOLI for the group with financial burden was 35.00 (25.0-50.0). The relevant scores of the group without financial burden was 40.00 (35.0-55.0). There was a statistically significant difference between these two groups $(p=0.012)$.

Cronbach alpha level for the domains I,II,II and IV were respectively $0.906,0.880,0.803$ and 0.682 .

\section{Discussion}

The PQOLI was developed upon context specific evidence of the study setting. It includes 21 items under four domains of physical/social, pain/emotional, financial stability and environmental domains. Hence it addresses many of the deficiencies of utilizing current QOL measures within the resource-constrained settings [26-29, 31].

Many of the recommended methodological aspects in the development of QOL tools were adhered in the development of the PQOLI [44]. As recommended in global literature, patients too were involved in several components of the study including the phase of item generation [33, 69]. The factorability assessments done by KMO measure, Barlett test, item communalities and anti-correlation images were satisfactory $[57,70,71]$. The KMO measure was more than 0.8 and hence can be classified as "meritorious" [57]. The significant Barlett test suggests that the "correlation matrix was significantly different from the identity matrix and therefore factorable" [57].

Exploratory Factor Analysis is better suited when the domain structure is not previously known as in this study [70]. Principal Component Analysis assumes the continuous nature of the variables and it was ensured by the presence of six response categories for each item [71]. It was performed following that with the intention of having a smaller number of variables that explain the most variation in the original set. Even though the orthogonal varimax rotation is commonly done, as in the present study, oblique techniques have been recommended in some literature $[69,72]$. A minimal eigenvalue of 1 is traditionally used in defining the factors as in the present study [61]. All the items had a loading value more than the traditional cut-off of 0.32 [69]. The complex factors with cross-loadings were dealt with internal consistency analysis $[69,72,73]$ The Cronbach's alpha values with "items removed" suggest that the allocation of cross loadings were accurate [74].

PQOLI is a disease-specific QOL tool in contrast to generic tools [75]. Disease-specific tools are considered better than generic tools for being more sensitive in picking the changes of stroke patients [33]. The present 
Table 5 Correlation of domain scores of PQOLI with SF-36 and EQ-5D

\begin{tabular}{|c|c|c|c|c|}
\hline & $\begin{array}{l}\text { Domain I Correlation }\left(r_{s}\right)^{a} \\
\text { Significance }\end{array}$ & $\begin{array}{l}\text { Domain II Correlation }\left(r_{s}\right)^{a} \\
\text { Significance }\end{array}$ & $\begin{array}{l}\text { Domain III Correlation }\left(r_{s}\right)^{a} \\
\text { Significance }\end{array}$ & $\begin{array}{l}\text { Domain IV Correlation }\left(r_{s}\right)^{a} \\
\text { Significance }\end{array}$ \\
\hline General Health & $0.352 p<0.001^{b}$ & $0.249 p<0.001^{b}$ & $0.195 p<0.001^{b}$ & $0.296 p<0.001^{b}$ \\
\hline Physical function & $0.792 p<0.001^{\mathrm{b}}$ & $0.416 p<0.001^{b}$ & $0.476 p<0.001^{b}$ & $0.667 p<0.001^{b}$ \\
\hline Pain & $0.761 p<0.001^{\mathrm{b}}$ & $0.405 p<0.001^{b}$ & $0.485 p<0.001^{b}$ & $0.612 p<0.001^{b}$ \\
\hline RL- physical & $0.581 p<0.001^{\mathrm{b}}$ & $0.524 p<0.001^{\mathrm{b}}$ & $0.468 p<0.001^{b}$ & $0.372 p<0.001^{b}$ \\
\hline RL- emotional & $0.502 p<0.001^{b}$ & $0.343 p<0.001^{b}$ & $0.481 p<0.001^{b}$ & $0.382 p<0.001^{b}$ \\
\hline Vitality & $0.403 p<0.001^{\mathrm{b}}$ & $0.388 p<0.001^{b}$ & $0.305 p<0.001^{b}$ & $0.276 p<0.001^{b}$ \\
\hline Social functioning & $0.759 p<0.001^{b}$ & $0.408 p<0.001^{b}$ & $0.474 p<0.001^{b}$ & $0.570 p<0.001^{b}$ \\
\hline Mental Health & $0.343 p<0.001^{b}$ & $0.340 p<0.001^{b}$ & $0.476 p<0.001^{b}$ & $0.339 p<0.001^{b}$ \\
\hline EQ-5D index & $0.845 p<0.001^{\mathrm{b}}$ & $0.489 p<0.001^{\mathrm{b}}$ & $0.563 p<0.001^{b}$ & $0.812 p<0.001^{b}$ \\
\hline EQ-5D VAS & $0.745 p<0.001^{\mathrm{b}}$ & $0.381 p<0.001^{b}$ & $0.476 p<0.001^{\mathrm{b}}$ & $0.667 p<0.001^{b}$ \\
\hline
\end{tabular}

${ }^{\mathrm{a}}$ Spearman correlation-coefficient ${ }^{\mathrm{b}}$ significant association

RL-physical- Role-Limitations-physical

RL-Emotional- Role-Limitations-emotional

EQ-5D-Index- Index score of the Euro-QOL-5D tool

EQ-5D-VAS- Visual Analogue Scale score of Euro-QOL-5D tool

tool was developed to cover a recall period of seven days in contrast to the four-weeks recall period of SF-36 and momentary capturing of QOL by EQ-5D [35, 41]. The validity of PQOLI was assessed at one month from the end of acute-management of the stroke. In literature post-stroke QOL has been measured from one month up to five years [76]. The seven-day recall period and utilization at one-month were decided in considering the rehabilitation procedure of the study settings and by considering the quality of patient-responses in the pretesting period.

Following the factor analysis, financial and environmental components were identified as two domains in the PQOLI. This is an example of the recent global recommendation that domain structures for QOL tools for LMICs should be context specific [31]. Furthermore this proves the necessity of incorporating economic and environmental domains in QOL measurements [16-22]. In many LMICs like Sri Lanka, social-insurance systems are not found. The services not free-of-charge, may have to be achieved by out-of-pocket expenditure creating a potential financial burden. These may be the reasons for getting a financial-independence domain following factor analysis. Domain II proves that the stroke-survivorfriendliness of the lining environment and the accessibility to healthcare too are important in determining the quality of life.

The pattern of correlations, provides evidence that the a-priori hypotheses no.1 to no.4 are fulfilled. This reflects that the PQOLI was based on a reflective model in addition to the assessment with the "thought test" as recommended in the COSMIN checklist [44]. All the items can be assumed to be changed when the underlying construct changes [44]. In evaluating the construct validity by the correlations, significance, direction and effect size are generally considered [44]. However due to the "complexities of the constructs", the strength of associations cannot be expected to be interpreted in the exact way as in bivariate correlations. Since then, for the a priori-hypotheses 1 to 3 , the significance and the directions were included while the explorations of strengths were focused in hypothesis no.4 [77, 78].

The hypothesis no.4 was fulfilled in relation to domain I, but was not to a great extent for domain IV. The domain structure in the PQOLI and the SF-36 are not the same. As an example, the pain domain which is a separate entity in the SF-36, has been included in the domain IV of the PQOLI together with items related to emotional-health. This difference of the item-structure might be one reason for PQOLI domain IV not having a

Table 6 Discrimination ability of PQOLI

\begin{tabular}{llll}
\hline & Hospital group $(n=99)$ & Ambulatory group $(n=81)$ & Significance of differenc $^{\mathrm{a}}$ \\
\hline Domain I median (IQR) & $40.00(30.45-52.73)$ & $72.72(59.09-90.00)$ & $p<0.001^{\mathrm{b}}$ \\
Domain II median (IQR) & $50.00(40.00-60.00)$ & $60.00(50.00-85.00)$ & $p<0.001^{\mathrm{b}}$ \\
Domain III median (IQR) & $35.00(30.00-40.00)$ & $50.00(40.00-60.00)$ & $p<0.001^{\mathrm{b}}$ \\
Domain IV median (IQR) & $60.00(40.00-80.00)$ & $90.00(80.00-90.00)$ & $p<0.001^{\mathrm{b}}$ \\
\hline
\end{tabular}

${ }^{\mathrm{a} M a n n-W h i t n e y ~} \mathrm{U}$ test ${ }^{\mathrm{b}}$ Significant association

IQR Inter-Quartile-Range 
greater strength with the mental-health, vitality and role-limitation-emotional domains of SF-36. However, the strength of associations were still of "acceptable and of medium strength" [77-79].

As expected the domain scores of PQOLI were significantly higher for the ambulatory group than the hospitalized group. This highlights its ability to discriminate between the severities of a spectrum. Institutionalized patients are with a higher severity of illness than the patients in the ambulatory group whom have been discharged from the in-ward care. This fulfills the a-prori hypothesis no.5. Hypothesis no. 6 tested the ability of the Domain III to discriminate between groups with differences in the level of financialindependence. A lower financial-independence in the group with "financial-burden" would have lowered their subjective perception of the position of living, thus lowering the QOL. This has been accurately captured by the Domain III of PQOLI. In a summary, five of the six a-priori hypotheses have been completely fulfilled and one has been partially fulfilled. Since the alpha values for domains I,II and III were more than 0.8 and for domain IV being closer to 0.7 , it can be classified as demonstrating satisfactory internal consistency [44, 70, 80].

Several limitations can be mentioned in this process. One is that the PQOLI provides only numerical outcome-scores for the domains without providing a categorical outcome as "satisfactory" and "not-satisfactory". This is acceptable as establishing a cut-off needs research in larger scale and it would be a future extension of this. Secondly the PQOLI provides 4 domain scores rather than an amalgamated score. Such a score would need weighing of the domains and that too would be done as a future extension of this research which would be done in a larger scale. The tool underwent exploratory factor analysis and it was not followed by confirmatory factor analysis in another study sample. Hence it is advisable to conduct confirmatory-factor analysis when this is used in another setting.

The reproducibility was not assessed for PQOLI and only the internal consistency reliability was assessed [80-82]. Similarly the responsiveness of the instrument was also not assessed [50, 51]. These reflect further directions on the future research $o$ PQOLI. There were limited descriptive data on the characteristics of the study sample. Though this was done to minimize the time of data collection, it is another limitation of the study. However, in order to minimize any selection bias, participants with a history of physical or mental conditions that would affect the quality of life were excluded. Furthermore, the study settings were with free healthcare and were without any restriction of access [83].

\section{Conclusions}

PQOLI included 21 items which are categorized under 04 domains in its development. There is first evidence for sufficient construct validity of the PQOLI as a valid QOL tool for measuring the QOL of stroke survivors with satisfactory internal consistency reliability, when assessed using already validated QOL tools and with the "known group comparison method". Five out of the six a-prori hypotheses were completely fulfilled in testing it for validity. Its internal consistency reliability was reflected to be satisfactory. PQOLI can be used for the assessment of QOL after 1 month from the end of acute-phase of management of the stroke survivors, following further explorations.

\section{Supplementary information}

Supplementary information accompanies this paper at https://doi.org/10. 1186/s12955-020-01436-7.

Additional file 1. PubMed search strategy. Mendeley search terms. Additional file 2. Domain analyses of commonly used QOL tools for stroke patients.

\begin{abstract}
Abbreviations
QOL: Quality of Life; PQOLI: Post-stroke Quality Of Life Index; COSMIN: COnsensus-based Standards for the selection of health Measurement Instruments; WHO: World Health Organization; SF-36: Short Form 36; EQ-5D-3 L: EuroQOL 5-Dimentional 3-level questionnaire; EQVAS: EuroQOL Visual Analogue Scale; LHS: London Handicap Scale; NHP: Nottingham Health Profile; SIP: Sickness Impact Profile; KMO: KaiserMeyer-Olkin
\end{abstract}

\section{Acknowledgements}

The authors would like to acknowledge Prof Nalika Gunawardene for her technical inputs on the preparation of the manuscript and for the provision of validated SF-36 questionnaire free-of-charge. Furthermore the authors like to acknowledge the EuroQOL group for providing the translated version of EQ-5D-3 L (Registration ID:6554) and the dataset for the determination of EQ5D-Index values free-of-charge.

\section{Authors' contributions}

All authors were involved in the planning of the research study. PKB was the principal investigator and involved in getting ethics permissions, data collection, data analysis and writing of the manuscript. MW, S, SM, SN were involved in data analysis, data interpretation and writing of the manuscript All authors went through the final manuscript. The author(s) read and approved the final manuscript.

\section{Funding}

The study was self-funded and was not funded by a third party.

\section{Availability of data and materials}

The datasets used and/or analyzed during the current study are available from the corresponding author on reasonable request.

\section{Ethics approval and consent to participate}

Ethics approval was obtained from the Ethics Review Committee of Sri Lanka Medical Association prior to the data collection (Reference number: ERC/14019 approval was given on 27th August 2014). Informed written consent was obtained from the participants.

Consent for publication Not applicable. 


\section{Competing interests}

The authors declare that they have no competing interests.

\section{Author details}

'Office of Regional Director of Health Services, Colombo, Sri Lanka. ${ }^{2}$ Department of Community Medicine, Faculty of Medicine, University of Colombo, Colombo, Sri Lanka. ${ }^{3}$ Department of Clinical Medicine, Faculty of Medicine, University of Colombo, Colombo, Sri Lanka. ${ }^{4}$ Colombo East Base Hospital, Colombo, Sri Lanka.

Received: 11 October 2018 Accepted: 4 June 2020 Published online: 20 July 2020

\section{References}

1. Thorvaldsen P, Kuulasmaa K, Rajakangas A-M, Rastenyte D, Sarti C, Wilhelmsen L. Stroke trends in the WHO MONICA project. Stroke. 1997;28(3): 500-6. https://doi.org/10.1161/01.STR.28.3.500.

2. McKay J, Mensah GA, Mendis S, Greenlund K. The atlas of heart disease and stroke. Geneva: World Health Organization; 2004. http://www.who.int/iris/ handle/10665/43007.

3. Yan LL, Li C, Chen J, et al. Prevention, management, and rehabilitation of stroke in low- and middle-income countries. eNeurologicalSci. 2016;2:21-30. https://doi.org/10.1016/j.ensci.2016.02.011.

4. The World Bank. Sri Lanka- Overview. https://www.worldbank.org/en/ country/srilanka/overview. Published 2020.

5. Smith O. Sri Lanka: achieving pro-poor universal health coverage without health financing reforms; 2018.

6. Chang T, Gajasinghe S, Arambepola C. Prevalence of stroke and its risk factors in urban Sri Lanka: population-based study. Stroke. 2015;46(10):29658. https://doi.org/10.1161/STROKEAHA.115.010203.

7. De Silva R, Gamage R, Wewelwala C, et al. Young strokes in Sri Lanka: an unsolved problem. J Stroke Cerebrovasc Dis. 2009;18(4):304-8. https://doi. org/10.1016/j.jstrokecerebrovasdis.2008.11.004.

8. WHO. Development of the World Health Organization WHOQOL-BREF quality of life assessment. The WHOQOL group. Psychol Med. 1998;28(3): 551-8 doi:10.5.12.

9. Mahesh PKB, Gunathunga MW, Jayasinghe S, Arnold SM, Haniffa R, De Silva AP. Pre-event quality of life and its influence on the post-event quality of life among patients with ST elevation and non-ST elevation myocardial infarctions of a premier province of Sri Lanka. Health Qual Life Outcomes. 2017;15(1):154. https://doi.org/10.1186/s12955-017-0730-9.

10. Kim JS, Choi-Kwon S, Kwon SU, Lee HJ, Park KA, Seo YS. Factors affecting the quality of life after ischemic stroke: young versus old patients. J Clin Neurol. 2005;1:59-68. https://doi.org/10.3988/jcn.2005.1.1.59.

11. Abubakar SA, Isezuo SA. Health related quality of life of stroke survivors: experience of a stroke unit. Int J Biomed Sci. 2012:8(3):183-7 http://www. ncbi.nlm.nih.gov/pubmed/23675271\%5Cn, http://www.pubmedcentral.nih. gov/articlerender.fcgi?artid=PMC3615283.

12. Xie G, Laskowitz DT, Turner EL, et al. Baseline health-related quality of life and 10-year all-cause mortality among 1739 Chinese adults. Schooling CM, ed. PLoS One. 2014;9(7):e101527. https://doi.org/10.1371/journal.pone. 0101527.

13. Salinas J, Sprinkhuizen SM, Ackerson T, et al. An international standard set of patient-centered outcome measures after stroke. Stroke. 2016:47(1):180-6. https://doi.org/10.1161/STROKEAHA.115.010898.

14. Oeyen SG, Vandijck DM, Benoit DD, Annemans L, Decruyenaere JM. Quality of life after intensive care: a systematic review of the literature. Crit Care Med. 2010;38(12):2386-400. https://doi.org/10.1097/CCM.0b013e3181f3dec5.

15. Winters BD, Eberlein M, Leung J, Needham DM, Pronovost PJ, Sevransky JE. Long-term mortality and quality of life in sepsis: a systematic review. Crit Care Med. 2010;38(5):1276-83. https://doi.org/10.1097/CCM. Ob013e3181d8cc1d.

16. Herridge MSMS, Cheung AMAM, Tansey CMCM, et al. One-year outcomes in survivors of the acute respiratory distress syndrome. N Engl J Med. 2003; 348(8):683-93. https://doi.org/10.1056/NEJMoa022450.

17. Griffiths JA, Barber VS, Cuthbertson BH, Young JD. A national survey of intensive care follow-up clinics. Anaesthesia. 2006;61(10):950-5. https://doi. org/10.1111/j.1365-2044.2006.04792.x.

18. Pappa E, Chatzikonstantinidou S, Chalkiopoulos G, Papadopoulos A, Niakas D. Health-related quality of life of the Roma in Greece: the role of socio- economic characteristics and housing conditions. Int J Environ Res Public Health. 2015;12(6):6669-81. https://doi.org/10.3390/ijerph120606669.

19. Thumboo J, Fong KY, Machin D, et al. Quality of life in an urban Asian population: the impact of ethnicity and socio-economic status. Soc Sci Med. 2003;56(8):1761-72. https://doi.org/10.1016/S0277-9536(02)00171-5.

20. Hamidou Z, Baumstarck K, Chinot O, et al. Domains of quality of life freely expressed by cancer patients and their caregivers: contribution of the SEIQoL. Health Qual Life Outcomes. 2017;15(1):99. https://doi.org/10.1186/ s12955-017-0672-2.

21. Post M. Definitions of quality of life: what has happened and how to move on. Top Spinal Cord Inj Rehabil. 2014;20(3):167-80. https://doi.org/10.1310/ sci2003-167.

22. Pietersma $\mathrm{S}$, de Vries $\mathrm{M}$, van den Akker-van Marle ME. Domains of quality of life: results of a three-stage Delphi consensus procedure among patients, family of patients, clinicians, scientists and the general public. Qual Life Res. 2013. https://doi.org/10.1007/s11136-013-0578-3.

23. Angus DC, Carlet J. Surviving intensive care: a report from the 2002 Brussels roundtable. Intensive Care Med. 2003;29(3):368-77. https://doi.org/10.1007/ s00134-002-1624-8.

24. Ezejimofor MC, Chen Y-F, Kandala N-B, et al. Stroke survivors in low- and middle-income countries: a meta-analysis of prevalence and secular trends. J Neurol Sci. 2016;364:68-76. https://doi.org/10.1016/j.jns.2016.03.016.

25. Thrift AG, Arabshahi S. Is stroke incidence in low- to middle-income countries driven by economics? Int J Stroke. 2012;7(4):307-8. https://doi.org/ 10.1111/j.1747-4949.2012.00819.x.

26. Alim M, Lindley R, Felix C, et al. Family-led rehabilitation after stroke in India: the ATTEND trial, study protocol for a randomized controlled trial. Trials. 2016;17(1):13. https://doi.org/10.1186/s13063-015-1129-8.

27. Sajjad A, Chowdhury R, Felix JF, et al. A systematic evaluation of stroke surveillance studies in low- and middle-income countries. Neurology. 2013; 80(7):677-84. https://doi.org/10.1212/WNL.0b013e318281cc6e.

28. Khalid W, Rozi S, Ali TS, et al. Quality of life after stroke in Pakistan. BMC Neurol. 2016;16(1):250. https://doi.org/10.1186/s12883-016-0774-1.

29. Stenumgård PS, Rakotondranaivo MJ, Sletvold O, Follestad T, Ellekjær $\mathrm{H}$. Stroke in a resource-constrained hospital in Madagascar. BMC Res Notes. 2017:10(1):307. https://doi.org/10.1186/s13104-017-2627-4.

30. Langhammer B, Sunnerhagen KS, Stanghelle JK, Sällström S, Becker F, FuglMeyer K. Life satisfaction in persons with severe stroke - a longitudinal report from the Sunnaas International Network (SIN) stroke study. Eur Stroke J. 2017;2(2):154-62. https://doi.org/10.1177/2396987317695140.

31. Samsiah M, Das S, Chee SY, et al. The ideal measurement of the quality of life in post stroke patients: an urban study. Clin Ter. 2011;162(3):209-15 http://www.ncbi.nlm.nih.gov/pubmed/21717044.

32. Garratt A, Schmidt L, Mackintosh A, Fitzpatrick R. Quality of life measurement: bibliographic study of patient assessed health outcome measures. Bmj. 2002; 324(7351):1417. https://doi.org/10.1136/bmj.324.7351.1417.

33. Kranciukaite D, Rastenyte D. Measurement of quality of life in stroke patients. Medicina (Kaunas). 2006;42(9):709-16 http://www.ncbi.nlm.nih.gov/ pubmed/21717044.

34. Thompson DR, Yu C-M. Quality of life in patients with coronary heart disease-l: assessment tools. Health Qual Life Outcomes. 2003;1(1):42. https:// doi.org/10.1186/1477-7525-1-42.

35. Ware JE, Snow KK, Kosinski M, Gandek B. SF-36 health survey manual and interpretation guide. Bost New Engl Med Cent. 1993:1 v. (various pagings) http:// books.google.com/books/about/SF_36_health_survey.html?id=WJsgAAAAMAAJ.

36. $S P, V S, B Z, M M, P T, P E$. Quality of life of stroke patients and their caregivers. Int J Phys Med Rehabil. 2017;05(01). https://doi.org/10.4172/23299096.1000387.

37. Mallawarachchi DSV. Quality of life of stroke patients presenting to selected hospitals in the Colombo District and the possibility of common mental disorders among the principal informal caregivers. MD Community Medicine, Post Graduate Institute of Medicine, University of Colombo.; 2007.

38. Rachpukdee S, Howteerakul N, Suwannapong N, Tang-aroonsin S. Quality of life of stroke survivors: a 3-month follow-up study. J Stroke Cerebrovasc Dis. 2013;22(7):e70-8. https://doi.org/10.1016/j.jstrokecerebrovasdis.2012.05.005.

39. Mahesh PKB, Gunathunga MW, Jayasinghe S, Arnold SM, Liyanage SN. Factors influencing pre-stroke and post-stroke quality of life among stroke survivors in a lower middle-income country. Neurol Sci. 2018;39(2):287-95. https://doi.org/10.1007/s10072-017-3172-6.

40. Gunawardena NS, Seneviratne SRA, Atauda T. An approach to validation of a multi-dimensional tool. J Coll Community Physicians Sri Lanka. 2003;8:18-26. 
41. Reenen M, Oppe M. EQ-5D-3L User Guide. Netherland: EuroQol Research Foundation; 2015

42. Mahesh P.K.B, Gunathunga M.W.JS. Influence of social determinants on the disease-outcome, financial burden and quality of life after a critical illness due to chronic Non Communicable Diseases, among patients treated at government hospitals in the Western province of Sri Lanka. 2015.

43. Kularatna S, Whitty JA, Johnson NW, Jayasinghe R, Scuffham PA. EQ-5D-3L derived population norms for health related quality of life in Sri Lanka. Bammann K, ed. PLoS One. 2014;9(11):e108434. https://doi.org/10.1371/journal.pone.0108434.

44. Mokkink $L B$, Terwee CB, Knol DL, et al. The COSMIN checklist for evaluating the methodological quality of studies on measurement properties: a clarification of its content. BMC Med Res Methodol. 2010;10(1):22. https:// doi.org/10.1186/1471-2288-10-22.

45. Mokkink LB, Terwee CB, Patrick DL, et al. The COSMIN study reached international consensus on taxonomy, terminology, and definitions of measurement properties for health-related patient-reported outcomes. J Clin Epidemiol. 2010;63(7):737-45. https://doi.org/10.1016/j.jclinepi.2010.02.006.

46. Banks JL, Marotta CA. Outcomes validity and reliability of the modified Rankin scale: implications for stroke clinical trials - a literature review and synthesis. Stroke. 2007;38(3):1091-6. https://doi.org/10.1161/01.STR. 0000258355.23810.c6.

47. Abramson JH, Abramson Z. Survey methods in community medicine. 5th ed. Edinburgh: Churchil Livingstone; 1999.

48. Richardson J, lezzi A, Khan MA, Maxwell A. Validity and reliability of the assessment of quality of life (AQoL)-8D multi-attribute utility instrument. Patient. 2014;7(1):85-96. https://doi.org/10.1007/s40271-013-0036-X.

49. Tang W, Cui Y, Babenko O. Internal consistency: do we really know what it is and how to assess it? J Psychol Behav Sci. 2014;2(2):205-20.

50. Angst $F$. The new COSMIN guidelines confront traditional concepts of responsiveness. BMC Med Res Methodol. 2011;11(1):152. https://doi.org/10. 1186/1471-2288-11-152.

51. Alderman N, Williams C, Knight C, Wood RL. Measuring change in symptoms of neurobehavioural disability: responsiveness of the St Andrew's-Swansea neurobehavioural outcome scale. Arch Clin Neuropsychol. 2017:1-12. https://doi.org/10.1093/arclin/acx026.

52. Ranawaka UK. Stroke care in Sri Lanka: the way we were, the way we are, and the way forward. J Stroke Med. 2018;1(1):45-50. https://doi.org/10.1177/ 2516608518774167.

53. Buck D, Jacoby A, Massey A, Ford G. Evaluation of measures used to assess quality of life after stroke. Stroke. 2000;31(8):2004-10. https://doi.org/10. 1161/01.STR.31.8.2004

54. Streiner DL, Norman GR. Health measurement scales: a practical guide to their development and use, vol. 14; 2008. https://doi.org/10.1378/chest.96.5.1161.

55. Tsang S, Royse CF, Terkawi AS. Guidelines for developing, translating, and validating a questionnaire in perioperative and pain medicine. Saudi J Anaesth. 2017;11(Suppl 1):S80-9. https://doi.org/10.4103/sja.SJA_203_17.

56. Osborne JW, Costello AB. Sample size and subject to item ratio in principal components analysis. Pract Assesment Res Eval. 2004.

57. Hauben $M$, Hung $E$, Hsieh W-Y. An exploratory factor analysis of the spontaneous reporting of severe cutaneous adverse reactions. Ther Adv Drug Saf. 2017:8(1):4-16. https://doi.org/10.1177/2042098616670799.

58. Mahesh PKB, Gunathunga MW, Jayasinghe $S$, et al. Financial burden of survivors of medically-managed myocardial infarction and its association with selected social determinants and quality of life in a lower middle income country. BMC Cardiovasc Disord. 2017;17(1):251. https://doi.org/10. 1186/s12872-017-0687-y.

59. Luo N, Chew LH, Fong KY, et al. Validity and reliability of the EQ-5D selfreport questionnaire in Chinese-speaking patients with rheumatic diseases in Singapore. Ann Acad Med Singap. 2003;32(5):685-90.

60. Rosales RS, Martin-Hidalgo Y, Reboso-Morales L, Atroshi I. Reliability and construct validity of the Spanish version of the 6-item CTS symptoms scale for outcomes assessment in carpal tunnel syndrome. BMC Musculoskelet Disord. 2016;17(1):115. https://doi.org/10.1186/s12891-016-0963-5.

61. O'Brien KK, Solomon P, Bergin C, et al. Reliability and validity of a new HIVspecific questionnaire with adults living with HIV in Canada and Ireland: the HIV Disability Questionnaire (HDQ). Health Qual Life Outcomes. 2015;13(1): 124. https://doi.org/10.1186/s12955-015-0310-9.

62. Paradowski PT, Keska R, Witoński D. Validation of the Polish version of the Knee injury and Osteoarthritis Outcome Score (KOOS) in patients with osteoarthritis undergoing total knee replacement. BMJ Open. 2015;5(7): e006947. https://doi.org/10.1136/bmjopen-2014-006947.
63. Cho E, Kim S. Cronbach's coefficient alpha: well known but poorly understood. Organ Res Methods. 2015. https://doi.org/10.1177/ 1094428114555994

64. Kothari RU, Pancioli A, Liu T, Brott T, Broderick J. Cincinnati prehospital stroke scale: reproducibility and validity. Ann Emerg Med. 1999;33(4):373-8. https://doi.org/10.1016/S0196-0644(99)70299-4.

65. Williams Weinberger M, Harris LE, Clark DO, Biller JLS. Stroke-specific quality of life scale. Stroke. 1999;30(7):1362-9.

66. Collin C, Wade DT, Davies S, Horne V. The Barthel ADL index: a reliability study. Int Disabil Stud. 1988;10(2):61-3. https://doi.org/10.3109/ 09638288809164103

67. Gerety MB, Cornell JE, Mulrow CD, et al. The sickness impact profile for nursing homes (SIP-NH). J Gerontol. 1994;49(1):M2-8 http://www.embase. $\mathrm{com} /$ search/results? subaction=viewrecord\&from $=$ export\&id $=L 24028007 \% 5$ Cn, http://resolver.ebscohost.com/openurl?custid=s3733374\&authtype= ip\&\&sid=EMBASE\&issn=00221422\&id=doi:\&atitle=The+Sickness + Impact + Profile+for+Nursing+Homes+\%28SIP-NH\%29\&sti.

68. Schuling J, de Haan R, Limburg M, Groenier KH. The Frenchay activities index. Assessment of functional status in stroke patients. Stroke. 1993;24(8): 1173-7. https://doi.org/10.1093/AGEING/12.2.166.

69. Farnik M. Instrument development and evaluation for patient-related outcomes assessments. Patient Relat Outcome Meas. 2012;1. https://doi.org/ 10.2147/PROM.S14405.

70. Kim H, Ku B, Kim JY, Park Y-J, Park Y-B. Confirmatory and exploratory factor analysis for validating the phlegm pattern questionnaire for healthy subjects. Evid Based Complement Alternat Med. 2016;2016:1-8. https://doi. org/10.1155/2016/2696019

71. Rhemtulla M, Brosseau-Liard PÉ, Savalei V. When can categorical variables be treated as continuous? A comparison of robust continuous and categorical SEM estimation methods under suboptimal conditions. Psychol Methods. 2012;17(3):354-73. https://doi.org/10.1037/a0029315.

72. Yong $A G$, Pearce $S$. A beginner's guide to factor analysis: focusing on exploratory factor analysis. Tutor Quant Methods Psychol. 2013;9(2):79-94. https://doi.org/10.20982/tamp.09.2.p079.

73. Rochette SBM. Guidelines for using exploratory factor analysis to test construct validity of inventories in sports research. Am J Sport Train. 2016:3 http://www.ajst.science/article/417/.

74. Santos JRA. Cronbach's alpha: a tool for assessing the reliability of scales. J Ext. 1999:37(2):1-5 http://www.joe.org/joe/1999april/tt3.php?ref.

75. Asadi-Lari M, Tamburini M, Gray D. Patients' needs, satisfaction, and health related quality of life: towards a comprehensive model. Health Qual Life Outcomes. 2004:2(1):32. https://doi.org/10.1186/1477-7525-2-32.

76. Katona M, Schmidt R, Schupp W, Graessel E. Predictors of health-related quality of life in stroke patients after neurological inpatient rehabilitation: a prospective study. Health Qual Life Outcomes. 2015;13(1):58. https:/doi.org/ 10.1186/s12955-015-0258-9.

77. Swank JM, Mullen PR. Evaluating evidence for conceptually related constructs using bivariate correlations. Meas Eval Couns Dev. 2017;50(4): 270-4. https://doi.org/10.1080/07481756.2017.1339562.

78. Watson JC, Flamez B. Counseling assessment and evaluation: fundamentals of applied practice. Thousand Oaks: Sage; 2015.

79. Sink C, Stroh H. Practical significance: the use of effect sizes in school counseling research. Prof Sch Couns. 2006. https://doi.org/10.5330/prsc.9.4. $283746 k 664204023$.

80. Kimberlin CL, Winterstein AG. Validity and reliability of measurement instruments used in research. Am J Heal Pharm. 2008;65(23):2276-84. https://doi.org/10.2146/ajhp070364.

81. Paiva CE, Barroso EM, Carneseca EC, et al. A critical analysis of test-retest reliability in instrument validation studies of cancer patients under palliative care: a systematic review. BMC Med Res Methodol. 2014;14(1):8. https://doi. org/10.1186/1471-2288-14-8.

82. Fayers PM, Machin D. Quality of life: the assessment, analysis and interpretation of patient-reported outcomes: second edition; 2007. https:// doi.org/10.1002/9780470024522.

83. Mahesh PKB, Gunathunga MW, Jayasinghe S, et al. Construct validity and reliability of EQ-5D-3L for stroke survivors in a lower middle income setting. Ceylon Med J. 2019;64(2):52. https://doi.org/10.4038/cmj.v64i2.8891.

\section{Publisher's Note}

Springer Nature remains neutral with regard to jurisdictional claims in published maps and institutional affiliations. 